
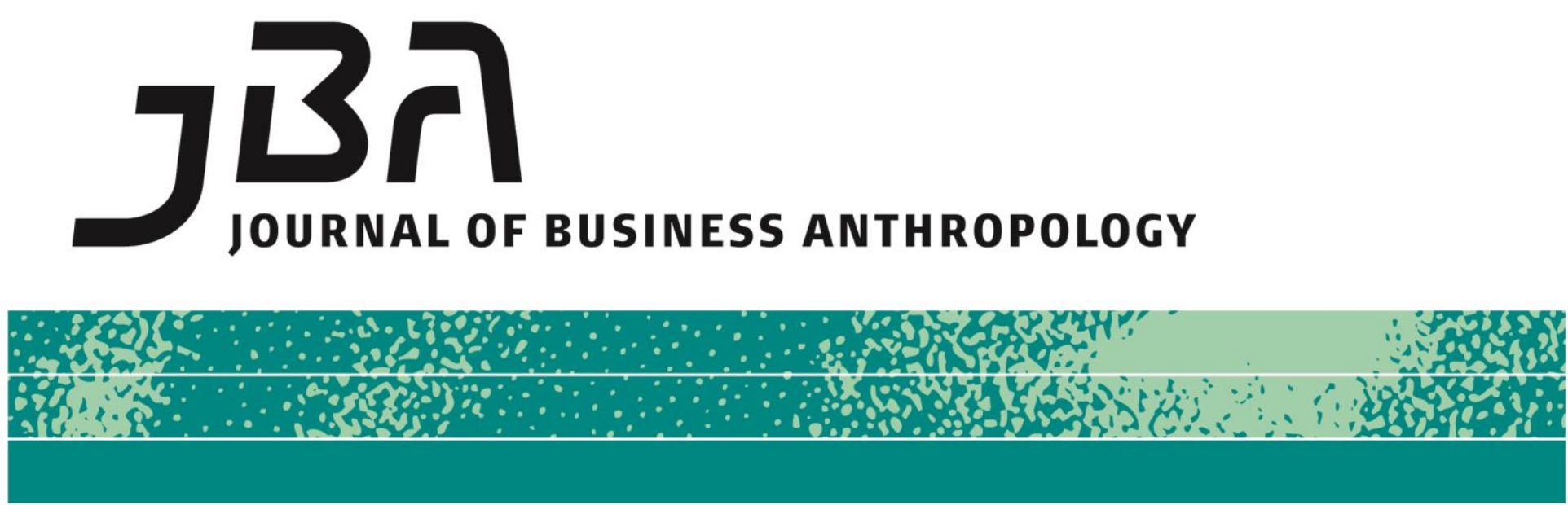

\title{
Ethics in Business Anthropology: Crossing Boundaries 1
}

Robert J. Morais and Timothy de Waal Malefyt

The door is the boundary between the foreign and domestic worlds in the case of an ordinary dwelling, between the profane and sacred worlds in the case of a temple. Therefore to cross the threshold is to unite oneself with a new world

(van Gennep 1960: 20)
Page 1 of 10

JBA Special Issue 1: 1-10, Spring 2014

(C) The Author(s) 2014 ISSN 2245-4217

www.cbs.dk/jba

The theme of the 2012 American Anthropological Association (AAA) meeting in San Francisco was 'Borders and Crossings.' A session on 'Ethics in Business Anthropology' seemed appropriate given the number of anthropologists increasingly crossing borders from academia to business and moving into business as a full-time career or operating between academia and business. The session that we planned would deal with the expanding notion of what crossing thresholds into a new world

\footnotetext{
${ }^{1}$ The articles in this issue are based upon papers presented in a session entitled 'Ethics in Business Anthropology' held at the 2012 meeting of the American Anthropological Association in San Francisco, California, USA. Some of the participants in that session elected not to include papers here and we invited Allen Batteau, who did not present a paper in that session, to join in this issue.
} 
(or at least a new community of commercial enterprises) means in terms of shared or contrasting values and moral obligations enveloping what anthropologists do. We were not surprised that the session was packed to capacity. Audience members queried the presenters and discussed a wide range of issues during and after the session ended. How should anthropologists who work in, for, and with for-profit corporations conduct their business as ethical anthropologists? How do or should different sets of ethical values co-exist between academic and commercial communities, which may seem at odds with one another? What is lost, gained, or in need of reevaluation in the interstices of border crossings? The questions raised and the answers offered during the AAA session were a beginning; the articles in this collection cover additional ground and add to the continuing and critical discourse on how to practice business anthropology ethically.

We begin here by first questioning what it means for anthropologists trained in vetting cultural understanding to 'cross borders' and enter a new world, as van Gennep suggests in the opening quote. This action indicates movement, but also along with it the diffusion and transformation of ideas, values, and principles in emplacement from one community to the other. Levi-Strauss ${ }^{2}$ argues in a talk on Race and Culture delivered to the United Nations (in Geertz 2000) that cultures or communities exhibit a tendency to cherish their own systemic values, and feel either enchanted by, or from a different angle, indifferent towards, other communities that are alien to them. He claims that cultures exhibit a form of ethnocentrism in this regard, and that this sentiment is actually not a bad thing. Geertz writes, citing Levi-Strauss, that loyalty to one set of values largely makes people insensitive to other values to which other people, equally parochial, are equally loyal (Geertz 2000: 70). In fact, Geertz continues with Levi-Strauss's quote, that 'cultures are not unaware of one another, they even borrow from one another on occasion; but, in order not to perish, they must in other connections remain somewhat impermeable toward one another' (Geertz 2000: 70). In this way, systems of values in one community are thus preserved even when in contact with other communities.

Geertz' discussion is central to the conundrum facing anthropologists more than ten years after his comments. Anthropologists increasingly must address the issue of how to deal with and study new forms of cultural diversity, as was relevant then to Geertz and LeviStrauss, and is as relevant for business anthropologists today as they contend with managing and producing results for corporations within and across an increasingly global society. The moral issue for anthropologists, Geertz claims, of building towards an understanding of integration of cultural diversity in other cultures different from our own,

2 Levi-Strauss, Claude. 1985 The View from Afar. Translated by J. Neugroschel and P. Hoss. New York: Basic Books. 
was in past years a concern across or between societies. However, now this is an issue that arises more than ever from within our own cultures. Just as there are Japanese in Brazil and Turks on main street, turning the lens on our own discipline, there are anthropologists working within and for other types of corporate communities altogether, which are not only profit-oriented transnational communities of diverse individuals themselves, but also contain their own ethical codes of professionalism and conduct.

We are in a new age of crossing boundaries with more diverse communities living and practicing within our own societies. And, clearly, we are not only examining subjects of study, but also forms of employment and commercialized exchange in complex economies. Just as earlier ideas of a universal hope for cross-cultural understanding have fallen away, and we realize that we can no longer surrender to the comforts of merely being ourselves and leaving others as they wish, anthropologists are also committed, claims Geertz, to the challenge of dealing with double lives from within our own discipline and our own communities. Geertz states: 'an anthropology so afraid of destroying cultural integrity and creativity, our own and everyone else's, by drawing near to other people, engaging them, seeking to grasp them in their immediacy and their difference, is destined to perish of an inanition for which no manipulations of objectivized data sets can compensate. In other words, he continues... 'when one has double citizenships' living in and with other communities 'one has double obligations' (Geertz 2000: 74-5).

The anthropologists who write in the following articles are embracing 'double citizenships with double obligations'; they function simultaneously as academy trained anthropologists and, either full-time or in a consulting role, as corporate employees, consultants, commercial designers, and market researchers. These articles address the issue of crossing boundaries, dealing with two or more sets of values, ethics, identities, and selves, functioning in two distinct communities, and hoping to make a difference in doing so or, at least, aiming to make a living.

Occupying these two worlds, living this duality of values and purpose, is not easy. The anthropologists who have authored these articles are engaged in a broad array of commercial initiatives, encompassing design, product development, consulting, and organizational research, among other areas. The involvement of anthropologists in these domains is sometimes ethically problematic given the demands of their sponsors - clients or others in control of their projects - not to mention the very nature of profit-driven commercial projects. The ethical codes of the American Anthropological Association, National Association of Practicing Anthropologists, and the Society for Applied Anthropology offer guidance, but they do not provide all the answers for those of us in business practice. Moreover, for these and 
other reasons stemming from anthropology's continual self-examination of its ethics, as discussed in several of the articles included here, skepticism about, even hostility to, commerce from within academia is palpable. This attitude persists even as the AAA has recognized the growth of applied anthropology and our discipline's increasing public engagement. The description of the 2013 AAA meeting, themed 'Future Publics, Current Engagements,' included the statement: 'the influence of anthropological methods, concepts and research is growing, as witnessed by the fact that over half of us are now employed outside the academy.'

There was recognition in the AAA's 2013 meeting agenda that ethics deserves special attention as anthropologists become more publically engaged: 'How do ethical considerations shape the practice but also the substance of our scholarship in an imperiled world?' The reference to an 'imperiled world' reminds us that much of applied anthropology is centered on 'doing good' rather than doing business. Anthropologists employed in industry applaud practicing anthropologists who focus on improving the lives of the disadvantaged and powerless; at the same time, these anthropologists make no apologies for participating in commercial endeavors. Consumption is the contemporary means by which people almost universally express their cultural identities and relate to one another (Miller 1995, 1998). Business acts as a mediator for supplies that people desire and, quite often, demand. Many anthropologists have focused on processes of exchange mediation in recent years, more from internal co-operative perspectives than antagonistically or from outside the system of exchange. As such, business anthropology can contribute to an understanding of customers' lives and to organizational operations ethnographically and theoretically, in addition to helping to generate corporate profits.

Any system of exchange between and within different communities presents potential conflicts, inequalities, and disparities. Anthropologists have historically debated over universalist or relativist perspectives in their engagement with local cultures (Geertz 1983). Anthropologists are now taking this debate to interactions among corporations, advertisers, marketers, distributors, and various types of consumers. Often at issue are short term versus longer term objectives, how corporate transparency, reciprocity, and community involvement can effectively benefit consumers, and how marketing can act as a positive force when value is considered from multiple perspectives. To be sure, business anthropology does present special ethical problems, and these challenges add a sense of urgency in discussing anthropological ethics. When anthropologists cross over to business, they often work with and for profit-driven corporations who 'own' the research findings, and these corporations have both known and unknown agendas for the uses of the work that anthropologists cannot control. Some projects in which business anthropologists engage raise specific ethical questions. How do anthropological practitioners assess which commercial projects may 
potentially harm or benefit the individuals or the communities they study? How should practitioners engage, reward, and communicate with their respondents? To whom and to what extent can and should practitioners make their commercial findings public? To whom are practitioners ultimately obligated: Clients? Consumers? Shareholders? The anthropological community? The public at large? How can ethical priorities be set, and is setting ethical priorities ethical?

Returning to the crossing borders theme from the AAA conference, many of the articles in this special JBA issue deal not only with dualities of values and purpose, but also with what a life of duality implies movement between and across disciplines. Movement in culture and commerce can provoke ethical quandaries. When anthropologists in business practices move, adjust, and adapt to circumstances, ethical issues often come to the fore. Movements are explored in the articles here in forms of displacement, replacement, culture contact, and corporate teamwork, where issues arise in ethical considerations of how best to sort things out. The authors consider what happens to constituents and the broader outcomes when shifts occur across disciplines such as between design and anthropology, or when working for transnational projects that cross disciplines and teams, or in balancing student/teacher projects and corporate culture barriers, or when working within and between departments in corporations, or even when reflecting on epistemological barriers in business anthropological practices across time and distance. These movements in values, behaviors, practices, and morals, between and among worlds of commerce and design, inevitably generate ethical questions for anthropologists who engage in business. Indeed, the work of anthropologists has always been about movement in and out of culture, in their particular practice of representing the social reality of others (Van Maanen 1988: ix). In this sense, movement creates an awareness of difference, which ultimately leads to knowledge and a better understanding of others (Bateson 1972).

Ethical considerations for anthropologists who cross borders into business entail carrying over one set of codes and values and adhering to another set that is likely different from those in anthropology. Communities may share many values and practices, while they contain distinct and sometimes conflicting rules for conduct. This was at issue in Elizabeth Briody and Tracy Meerwarth Pester's article, when they compare ethical codes set by the AAA (with some reference to the ethical codes of the National Association of Practicing Anthropologists and the Society for Applied Anthropology) with those of internal constituents at General Motors (GM). As they mention, often practicing anthropologists must straddle two or more worlds of work, each with its own ethical codes. Many applications of ethics do apply and cross over, such as honesty and stating the purpose and scope of the research, but others diverge. While the AAA code applies ethics to universal approaches in research, GM sets guidelines for achieving specific business results. In 
attempting to apply AAA ethical guidelines to GM organizational situations, Briody and Meerwarth Pester discover that the AAA offers little guidance in negotiating business situations, such as 'the muddy waters of power and hierarchy in real business settings.' The authors find that the crossing-over of ethical codes from the AAA to GM, as when they attempt to apply universalist ethics to particular situations in business, reveals the true complexities of mediating business outcomes.

Jo Aiken, Victoria Schlieder, and Christina Wasson question how to navigate the ethical quandaries inherent in the multiple pressures of doing fieldwork, as when students and a teacher conduct a project for a corporation and face ambiguities of 'exceptional circumstances' in research. Yet, what they discover is that because fieldwork often confronts exceptional circumstances, ambiguous circumstances can be viewed as the norm. We would add that, when they report a respondent consuming alcoholic beverages while cooking to be an exceptional circumstance, such behavior is often normal (consuming wine while cooking is common among chefs), and we would commend them for discovering a true 'natural' respondent. In fact, the students might have adapted to the situation further by questioning the respondent on the enjoyment of alcohol while cooking. But, again, Aiken, Schlieder, and Wasson rightly question the absoluteness of ethical conduct set by the American Anthropological Association, National Association of Practicing Anthropologists, and Society for Applied Anthropology - professional guidelines that strictly prohibit any form of drug use or alcohol consumption - when fieldwork encounters often present these kinds of circumstances. From a broader pedagogical perspective, the authors recognize that not all students come to ethical training with the same experiences or views and that ethical actions are not as black and white as students might wish. The article suggests valuable ways of teaching business anthropology ethics and navigating gray ethical areas in practice.

Christine Miller's article considers the responsibility and accountability of designers to their various publics in the context of how the discipline of design has changed its emphasis in recent years from object-oriented to human centered design. In shifting from object to user in design research, everyday users of design have become the subject of focus. Now, designers are faced with responding to the complex ways in which people behave, making ethics in design studies paramount. Other operational changes include adaptations in what designers now produce, since the design field has also moved from making craftwork of tangible objects to the subject of designing intangible services, process, interactions, and experiences. How do designers ethically navigate calls for increased consumption, concepts of identity, and issues of aesthetics, including notions of what constitutes beauty in objects? Miller explores the ethical questions that such movement provokes as human oriented outcomes become more abstract, complex, and contextual. 
Julia Gluesing's article looks closely at ethics in her global multinational work. Given that ethics are embedded in local culture, she questions how applications of transnational corporations and universalist principles set by the AAA can be applied to local situations. Confounding clear application of consistent ethics are the ways businesses now emphasize sustainable operating environments that are adopted to local environments, so that in her words, 'ethics becomes a moving target.' Gluesing concludes that multinational projects, which involve many shareholders with different backgrounds and aims, must be situated within local pragmatics to be ethical. Relativity in these ethical situations wins out over universal conduct codes, or in her words, 'practical wisdom' situates ethical practice in contextual circumstances.

This operating principle ties to a recurrent theme among the articles collected here - the question of universalist versus local and relativistic applications of ethics. Allen Batteau and Bradley Trainor address the complexity of this concern in a theoretical exploration of the ethical epistemes of anthropology's culture contact through time and distance, and how such contacts with the other relate to disparities and shifts of power in economies. New economies, new territories, and new practices created emergent relations and new forms of power, all of which led to dilemmas, morals, and fresh thinking on how ethical conduct, and ethics as a construct, should be defined. For anthropologists working in industry, they state, corporate encounters today necessitate an ethical response to such disparities.

While ethics in all these cases are about respecting relationships, acting with integrity for the individual and his organization, and how people in the field and at home may refer to universal principles, the practice of ethical and moral behavior is connected to the particularities and constraints of the situation at hand. This means business anthropologists in particular must know in a business situation not only the right thing to do, but as Gluesing states, the good thing to do. As Briody and Meerwarth Pester argue, 'do some good' is framed in the language of results, taking action, assuming responsibility and accountability for making a change for the better. This contrasts with the AAA guidelines for research anthropologists to do no harm, which derives from the ancient Hippocratic oath. The AAA's mandate of 'do no harm' calls for the field anthropologist to maintain the 'status quo,' make no waves, in other words, leave little impact. Yet, most industries and people working for industry are, by the very nature of their work, interventionists. They cannot abide by such inaction. Rather, business anthropological practitioners are not only in the midst of change, but often, as Briody and Meerwarth Pester point out, leading change in hope that some good will come of it. If anthropology is for making a difference, becoming a public advocate and a clarion of change, then 'doing some good' is a new mandate for practicing anthropologists to embrace, ethically and morally, even when the sponsor's goal is financial gain. In the latter cases, the 
ethical business anthropologist can help ensure that the gain is not at the expense of those who are studied.

This brings us to our own view on business anthropology ethics. ${ }^{3}$ As business anthropologists who work in advertising and marketing research, we hold in practice the belief shared by Miller (1995) and others that commerce often enriches culture when exchange is mutually beneficial. We maintain that marketing and advertising cannot be blamed unduly for concerns of over-consumption, unsustainability, inequalities in wealth, and access to commercial goods. Rather, 'doing some good' means informing the clients we work for of the best choice options in what they can deliver to their consumers. 'Doing some good' means our helping clients produce what consumers wish to consume. Consumer choice operates in the context of caveat emptor; this mode should be, and often is, the way people buy, especially in an era when purchase decisionmaking is highly informed and mediated by online search and critical social networks. Anthropologists who work in and on industry are certainly aware of consumer mindfulness and savvy. Marietta Baba (2006: 44) notes: 'consumers are not passive adopters of products,' and John Sherry (2008: 90) observes that consumers are neither 'cultural dopes [n]or cultural dupes'. Moreover, while we acknowledge marketing's agenda for profit, we also know that it is possible to deliver profit in a manner that benefits both consumers and corporations. Tom's Shoes, Body Shop, Zappos, and Amazon, among other corporations, are leading the way to increase their value by benefiting consumers more positively. These corporations, among others, practice "purpose based" marketing (also called pro-social marketing). The idea is to inform consumers about the way in which these companies operate in a socially responsible manner. In part, responding to the demand of socially responsible consumption, such companies practice 'fair trade' with coffee growers, work with charities such as Feeding America and open-donation community restaurants, or develop recycling or shoe donation programs that work with communities in need (Elliot 2013). Today, more than ever, marketing is responsive to the informed consumer because consumers demand it to be so, and because through the immediacy of the internet, best (and worst) practices of corporations are readily available for critical consumers to judge.

We realize that not all marketers consult with their customers or have their customers' best interests in mind, and some marketing and advertising points consumers toward specific brands in a way that benefits the manufacturer more than consumers. We understand some marketing agendas are ethically grey, and we rationalize our involvement in these practices by reminding ourselves that consumers can, and often do, reject marketing and advertising initiatives. Nevertheless, ethical

\footnotetext{
${ }^{3}$ We have detailed our thoughts on advertising and marketing ethics in Malefyt and Morais (2012).
} 
boundaries and moral questions as to the behavior of brands, profits and corporate agendas continue to be tested (and even crossed) since a primary function of capitalism and corporate success is based on advantage over others.

We consider the articles in this special JBA issue an impetus for further conversations on how to engage in an ethical anthropology in the still nascent crossings of anthropology into the commercial realm. We are cognizant that a limitation of this collection is that the articles discussed matters only within the sphere of the practitioners who wrote them. Reflection on business ethics more generally (for example, Shaw 2005) entails a far wider array of topics, some of which should concern business anthropologists depending upon the tasks they undertake. But still, anthropologists, because of our history and worldview, add unique sensibilities to the ethical and moral complexities of business practice. We encourage JBA readers to comment on the articles included here, add their experiences and perspectives to the discussion, and apply ethical conduct to their own practice.

\section{References}

Baba, Marietta. L. 2006. Anthropology and Business in H. J. Birx (ed.) Encyclopedia of Anthropology. Thousand Oaks, CA: Sage Publications.

Bateson, Gregory. 1972. Steps to an Ecology of Mind. New York: Chandler Publishing Company.

Elliot, Stuart. 2013. "Selling Products by Selling Shared Values." The New York Times, Business Section. February 13.

Geertz, Clifford. 2000. Available Light: Anthropological Reflections on Philosophical Topics. Princeton, NJ: Princeton University Press.

Geertz, Clifford. 1983. Local knowledge: Further Articles in Interpretive Anthropology. New York: Basic Books.

Malefyt, Timothy de Waal and Robert J. Morais. 2012. Advertising and Anthropology: Ethnographic Practice and Cultural Perspectives. Oxford: Berg.

Miller, Daniel. 1995. Acknowledging Consumption. London: Routledge.

Miller, Daniel. 1998 A Theory of Shopping. London: Routledge.

Shaw, William H. 2005. Business Ethics. Fifth Edition. Belmont, CA: Wadsworth.

Sherry, John F. 2008. The Ethnographer's Apprentice: Trying Consumer Culture from the Outside In. Journal of Business Ethics. 80: 85-95.

Van Gennep, Arnold. 1960. The Rites of Passage. Trans. M.B. Vigedom and G. L. Caffee. Chicago: University of Chicago Press. 
Van Maanen, John. 1988. Tales of the Field: On Writing Ethnography. Chicago: University of Chicago Press.

Robert J. Morais, Ph.D., is a Principal at Weinman Schnee Morais Inc, a New York based marketing research firm. He has worked in the advertising and marketing research industries for over 30 years. He is the author of Refocusing Focus Groups: A Practical Guide (2010) and the co-author of Advertising and Anthropology: Ethnographic Practice and Cultural Perspectives (2012). He can be reached at rmorais@wsminc.com.

Timothy de Waal Malefyt, Ph.D., is visiting Associate Professor at Fordham University in NYC. For 15 years he led strategy and brand development as VP, Director of Cultural Discoveries for BBDO Worldwide advertising in NYC, and D'Arcy, Masius, Benton \& Bowles in Detroit, for Cadillac. Dr. Malefyt is co-editor of Advertising Cultures (2003), and coauthor of Advertising and Anthropology (2012) He is cited in Business Week, New York Times, USA TODAY, BrandWeek, among other media. He can be reached at tmalefyt@fordham.edu 